\title{
La representación del terrorismo de ETA en el diario francés Le Monde
}

\section{The Coverage of the Terrorism of ETA in the French Newspaper Le Monde}

Elba Díaz Cerveró. Universidad CEU San Pablo

Recibido: 18-II-2009 - Aceptado: 1-VII-2009

Resumen:

El presente artículo es fruto de un amplio análisis de contenido que trata de mostrar cuál ha sido la representación o cobertura que ha hecho del terrorismo de ETA el diario francés Le Monde. Para ello se han abordado de forma exhaustiva todos los atentados mortales de la banda, desde el primero, en junio de 1968, hasta el último, en diciembre de 2008, partiendo de la hipótesis de un posible desinterés de la prensa francesa hacia el terrorismo de ETA, sin olvidar que este fenómeno ha determinado en muchas ocasiones las relaciones políticas y diplomáticas entre Francia y España.

Palabras clave:

Análisis de contenido, terrorismo, banda terrorista, ETA, prensa francesa, Le Monde, atentados mortales, Francia, España, relaciones internacionales.

Abstract:

This article is the result of a wide content analysis that tries to show how the French newspaper Le Monde has represented or covered the terrorism of ETA. In order to get it, all its mortal terrorist attacks have been dealt, from the first one, in June 1968, to the last one, in December 2008. The study starts from the hypothesis that considers the lack of interest of the French press to the terrorism of ETA, remaining this phenomenon has determined in a lot of occasions the politic and diplomatic relationships between France and Spain.

Key words:

Content Analysis, Terrorism, Terrorist Group, ETA, French Press, Le Monde, Mortal Terrorist Attacks, France, Spain, International Relationships. 


\section{Introducción}

El terrorismo siempre ha sido un foco de debate en los medios de comunicación. En España los atentados de ETA constituyen una de las primeras preocupaciones de los ciudadanos ${ }^{1} \mathrm{y}$, pese que algunos aún lo ponen en duda, las acciones terroristas han condicionado el rumbo electoral de éste y otros países. Es precisamente la española una sociedad desgraciadamente acostumbrada a la lacra del terrorismo, ya que este acompaña su devenir de forma más o menos continuada desde hace ya más de 40 años.

Los diferentes modos de informar de la prensa española al respecto del terrorismo constituyen un ámbito sobre el que mucho se ha investigado; sin embargo, poco se ha escrito sobre el tratamiento de la prensa francesa al terrorismo de ETA, aun cuando históricamente los miembros de la banda han hecho del país vecino su refugio, beneficiándose durante los primeros años 80 del estatus de Francia como tierra de asilo en Europa, y organizando allí robos de armas y algunos de los atentados que más tarde cometerían a este lado de la frontera.

Estos y muchos otros aspectos de la cooperación entre Francia y España en la lucha contra ETA han sido estudiados desde el ámbito de las relaciones diplomáticas entre ambos países (Morán, 1997), pero no desde el de la prensa. En esta disciplina, los estudios publicados se circunscriben al ámbito exclusivamente español, con investigaciones que se centran en períodos concretos. Tal es el caso de la tesis publicada por el profesor José Manuel Rivas Troitiño y titulada Desinformación y terrorismo: análisis de las conversaciones entre el Gobierno y ETA en Argel (enero-abril 1989) en tres diarios de Madrid (Rivas Troitiño, 1992) o la publicada por Francisco José Setién, que hace referencia a la cobertura que la prensa española hizo de ETA -tratada de forma conjunta con el resto de grupos terroristas que operaban en España en esa década- entre 1976 y 1986 (Setién, 1992).

Para dar una idea de la amplitud del estudio que aquí trata de sintetizarse, el trabajo de campo sobre el que se basa ha supuesto la consulta de aproximadamente 5.000 ejemplares de Le Monde, de los cuales -se avanza ya- se desprende un resultado compuesto por 654 piezas informativas -relacionadas directa o indirectamente con el terrorismo de ETA- seleccionadas de cualquier sección del vespertino galo, y dos editoriales. Para realizar la consulta se han visionado, por una parte, más de 300 rollos de microfilme -cada uno correspondiente a un mes del año- de la sala de microformas de la Biblioteca Nacional de España, en su sede principal en Madrid. El resto de ejemplares se han examinado, en formato papel, en la sede que la BNE tiene en Alcalá de Henares, así como en los fondos de la Hemeroteca General de la Universitat Autònoma de Barcelona.

Así lo muestran mes a mes los resultados del Barómetro del CIS. 
El posible desinterés de la prensa francesa hacia el terrorismo de ETA es la hipótesis que ha motivado el desarrollo del estudio. Desinterés tal vez motivado por la concepción del fenómeno como algo ajeno, dado el caso de que la banda, aun considerando también a Francia como país opresor de su pueblo, nunca ha tenido la intención -salvo puntuales excepciones- de llevar adelante acciones en el territorio del Estado Francés. Así lo han declarado en alguna ocasión los propios miembros de ETA quienes, para los estudiosos del terrorismo, "No se han interesado en atacar a Francia porque, incluso sin santuario [sic], la caza podría ser mayor si hubiera funcionarios franceses muertos” (Domínguez, 2002: 132).

Para llevar a cabo esta investigación, Le Monde ha sido el diario elegido por ser el principal periódico generalista francés, el segundo de mayor tirada y el mejor considerado por la clase dirigente. Además, el vespertino constituye una cabecera de referencia en el panorama internacional y una de las que a diario son consultadas en la Moncloa. Jacques Thibau, embajador, ex director de la segunda cadena de televisión francesa y autor del primer libro en el que narra la historia de Le Monde, lo define así: "Es en apariencia austero, pero constituye 'el' periódico de referencia, el que se debe leer porque confiere a la información una interpretación auténtica y su exacta importancia” (Thibau, 1996: 542).

La metodología llevada a cabo para desarrollar el estudio consta, como ya se ha anunciado en las primeras líneas, de un análisis de contenido que se divide en dos áreas: la relativa a los datos cuantitativos y la lexicográfica. En primer lugar, el análisis cuantitativo engloba doce categorías:

1. $\quad \mathrm{N}^{\circ}$ de víctimas $\mathrm{y} \mathrm{n}^{\circ}$ de atentados reales

2. $\mathrm{N}^{\circ}$ de atentados sobre los que informa Le Monde

3. No de noticias con seguimiento

4. No de veces en las que se produce silencio informativo

5. Profesión de las víctimas

6. Profesión de las víctimas sobre las que informa Le Monde

7. No de noticias o piezas informativas

8. No de veces en que ETA aparece en portada

9. No de veces en que ETA aparece en el titular

10. Noticias propias o de agencias 


\section{No fotos}

12. Disposición de las informaciones mayoritaria

Mediante este análisis cuantitativo se ha tratado de traducir a números la cobertura que Le Monde hace del terrorismo de ETA, con el fin de poder cuantificar y, posteriormente valorar, ya en un análisis cualitativo, si el tratamiento es adecuado y completo o, si por el contrario, es insuficiente y no se ajusta a la realidad del fenómeno en toda su magnitud. Este primer análisis se ha llevado a cabo contabilizando las víctimas mortales y los atentados reales, para compararlos con los que efectivamente cubre el diario. Además, se han tenido en cuenta las noticias con seguimiento, así como el número de veces y períodos en los que se produce silencio informativo. También se han valorado la profesión de las víctimas que efectivamente causó ETA y las de aquellas sobre las que informa Le Monde, a fin de poder establecer si esa cobertura proporciona una visión clara de la realidad.

Por otra parte, se ha contabilizado el número de noticias publicadas sobre la banda en Le Monde, las veces en que esas noticias han constituido tema de portada y en cuántas ocasiones ha aparecido el nombre de ETA en los titulares del periódico, con el fin de evaluar la visibilidad que el vespertino ha dado a la banda y a su propio nombre. Además, se ha valorado la cantidad de material gráfico con que se acompañan las informaciones, compuesto por las fotografías, viñetas, tablas, mapas o infográficos empleados para ilustrar las noticias sobre el terrorismo de ETA. Y, por último, el análisis cuantitativo concluye con la disposición de las informaciones mayoritaria en cada año.

En cuanto al análisis lexicométrico, se ha realizado un estudio exhaustivo del léxico empleado, contabilizando exactamente cuántos calificativos y expresiones en general utiliza Le Monde para referirse a ETA y a sus miembros y en cuántas ocasiones se repiten esos términos en cada uno de los años estudiados. Por último, se han puesto ejemplos que sirven para comprender la manera en que Le Monde informa sobre ETA y se han traducido todas aquellas noticias o piezas informativas significativas por su forma o contenido.

\section{El terrorismo en los medios de comunicación}

Los medios de comunicación como Le Monde desempeñan un papel fundamental en la percepción de la realidad que tienen sus audiencias (Núñez Ladevéze, 1979). Actúan como instituciones que influyen en las sociedades y éstas son persuadidas, especialmente, por la prensa escrita de referencia, ya que su tradición, imagen de seriedad y la confianza del lector en la firma que escribe hacen que disminuyan las objeciones acerca de si lo que se narra es cierto o no (Núñez Ladevéze, 2004: 395). 
Puesto que todos los medios tienen una línea editorial, esta siempre determinará la intensidad en la cobertura del acontecimiento. Además, según en qué sección aparezca la información, esta se redefinirá como suceso o como información política. En definitiva, la percepción del lector al respecto del terrorismo está determinada no tanto por lo que se cuenta o no se cuenta, sino por cómo se cuenta. A menudo, los periodistas caen en un uso mimético de la terminología terrorista, lo que hace que las expresiones empleadas, todas ellas de grandes connotaciones, sean reproducidas e interiorizadas por el lector. En una primera fase, son los terroristas quienes se encargan provocar esa manipulación, utilizando un término valorativo que intenta aminorar la posible carga negativa del campo semántico.

Si son ellos quienes los cometen, los asesinatos, crímenes o muertes son ejecuciones. Los secuestrados o rehenes son prisioneros. Los atentados son acciones u operaciones. A las extorsiones se les denomina impuesto revolucionario; a los presos acusados por un tribunal de un estado democrático en un juicio acorde a la ley se les denomina prisioneros y, aunque todo ello aparezca entre comillas, la descripción de los hechos de ese modo introduce un fuerte componente propagandístico.

\section{ETA en Le Monde}

Es curioso comprobar cómo el primer diario de referencia francés denomina "terroristas" a los miembros de Al Qaeda, a los del FLNC y a los grupos que actúan en la franja de Gaza y Cisjordania mientras que, a la finalización de este trabajo, todavía se refiere como "separatistas" o "independentistas" a los miembros de ETA y a la propia banda.

En el caso de Le Monde, y en lo que a ETA se refiere, sus corresponsales en España dan explicaciones de todo tipo. Por un lado, Martine Silber afirmaba en una entrevista concedida a Radio Cable que no se puede llamar organización terrorista a ETA "porque una organización no puede ser terrorista. Tenemos que decir que es una organización que comete atentados terroristas"2. Por otra parte, Cécile Chambraud explicaba en una entrevista personal que no es suficiente con llamar a los miembros de la banda terrorista, por lo que es frecuente recurrir a adjetivos como "separatistas"3. Ambas afirmaciones serían ciertas si las justificaciones de estas corresponsales se correspondieran con lo publicado en el diario, pero eso no ocurre y lo cierto es que el término "terrorista" aparece en cinco ocasiones aplicado a la banda y en trece a sus miembros en el total de las 654 noticias recogidas.

http://www.xpress.es/radiocable/esp-corresponsales.htm.

Entrevista de la autora con Cécile Chambraud, corresponsal de Le Monde en Madrid, 30 de junio de 2007. 
Por su parte, las agencias de noticias, que con sus informaciones muchas veces sustituyen a los propios redactores del periódico, contribuyen también a la percepción que tiene el lector del terrorismo. Así, mientras que Associated Press (AP) consideró a ETA como una guerrilla vasca hasta 2001 (Rivas Troitiño, 1992: 132), la Agence France Presse (AFP) tiene la consigna referirse a ETA como banda o grupo terrorista sólo internamente entre el personal de la agencia, pero nunca a la hora de publicar o vender los teletipos a los medios. Y esta constituye la única norma estilística de la agencia con respecto al tratamiento de ETA $^{4}$.

En ocasiones -y como ocurre en el caso de Le Monde al respecto del terrorismo de ETA-, bajo el manto de la comprometida y loable misión de informar, los medios de comunicación difunden un discurso determinado por lo que en él se cuenta o se silencia, por cómo se nombra lo que se cuenta y por quién lo cuenta. Todos estos aspectos, unidos a la suposición de la imparcialidad y el compromiso de los que los medios presumen, a menudo pasan desapercibidos para la audiencia y son los que hacen que el relato periodístico sobre la realidad terrorista sea asumido por quien lo recibe como válido en cualquier caso, sin que ese receptor se percate de un mensaje a menudo tan peligroso como las propias armas.

Como consecuencia, nos encontramos ante una sociedad desinformada y confusa, más todavía cuando confía en que el medio que utiliza para informarse, por llamarse "de referencia", no va a fallarle en aspectos tan importantes como el terrorismo. Podríamos decir que el estatus de un diario es inversamente proporcional al cuestionamiento que hacen sus lectores de los contenidos que publica, lo que produce la asunción del mensaje sin que haya lugar para la crítica. Esto se produce de forma especialmente intensa cuando el fenómeno terrorista perdura en el tiempo, por cuanto las informaciones se repiten cientos de veces con los mismos errores que el primer día.

Si a ello sumamos la incomprensión y los prejuicios iniciales hacia el problema, el resultado es el de una opinión pública desinteresada y ajena al fenómeno, que no se involucrará en él hasta que no le afecte directamente y a la que las informaciones repetitivas, muchas veces erróneas y casi idénticas entre sí, causarán tedio como única reacción.

Ese desinterés de la sociedad francesa parece haber sido motivado por la concepción del fenómeno como algo ajeno, dado el caso de que la banda, aun considerando también a Francia como país opresor de su pueblo, nunca ha tenido intención de llevar adelante acciones en el territorio del Estado Francés. Así lo han declarado en alguna ocasión los propios miembros de ETA quienes, para los estudiosos del terrorismo, "No

4 Entrevista de la autora con Virginie Grognou, corresponsal de AFP en Madrid. Valencia, 29 de marzo de 2007. 
se han interesado en atacar a Francia porque, incluso sin santuario [sic], la caza podría ser mayor si hubiera funcionarios franceses muertos" (Domínguez, 2006: 132).

\subsection{Primera etapa (1968-1979) : ETA como libertador de un pueblo oprimido}

Justo los años en que ETA cometía los primeros atentados mortales, Francia vivía hitos históricos como mayo del 68 o la dimisión del general Charles de Gaulle, en 1969. La sociedad francesa de este período poco tenía que ver con la española. Era rica, desarrollada y la educación secundaria y superior se extendía a un número creciente de jóvenes. Pero estos consideraban el cuerpo social como demasiado rígido, jerarquizado y bloqueado. Le Monde se hace eco de esas preocupaciones sociales y las refleja en sus páginas.

En una de las primeras informaciones sobre atentados de ETA que cubrió Le Monde, la visión del vespertino estuvo claramente posicionada, justificando el asesinato de Melitón Manzanas y retratando al jefe de policía como un "torturador conocido". A ello se unía la explicación de las siglas de ETA como "País Vasco y libertad" -traducción del nombre en euskera con el que se define la propia banda- y el calificativo "revolucionario" sumado a "grupo" o a “organización” como forma que más se repetía a la hora de representar a ETA hasta 1975.

Tras la muerte de Franco, la postura que las autoridades francesas mantuvieron fue la de tolerancia hacia ETA, ya que a cambio la banda mantendría controlado al nacionalismo vascofrancés (Morán, 1997: 103).

Le Monde informa en esos años de 80 atentados con un total de 155 víctimas, cuando, en realidad, los atentados mortales perpetrados por ETA fueron 128 y éstos causaron un total de 219 víctimas. Por lo tanto, la representación que el vespertino galo hace del terrorismo de ETA en esos años es del 51,6\% de los atentados mortales y del 58,4\% de las víctimas causadas por la banda, otorgando a los asesinados sin profesión específica una cobertura inferior al $20 \%$ o, lo que es lo mismo, haciéndoles invisibles a ojos del lector del diario en un $80 \%$ de las ocasiones.

En el ámbito del léxico, la expresión "organización separatista” constituía la forma generalizada con la que el vespertino denomina a ETA, mientras que a sus miembros los llamaba "militantes", como si la banda terrorista fuera un partido político más. Se puede avanzar ya que la fórmula "organización separatista" es, a lo largo de los años y hasta la actualidad, la expresión preferente con la que Le Monde designa a ETA. Para muchos estudiosos, como el catedrático Luis Núñez Ladevéze, esta selección lingüística de los periodistas -cuando se refieren a ETA sólo como "separatista" y excluyen el término "terrorista"- responde a una intencionalidad selectiva y una manipulación conceptual del lenguaje (Núñez Ladevéze, 1995: 32). 


\subsection{Segunda etapa: 1980, el año con más atentados de ETA}

De las casi cuatro décadas de existencia de la banda, en 1980 ETA causó el mayor número de víctimas mortales y, aunque 1979 fue más trágico si se tienen en cuenta todos los tipos de terrorismo que operaban en aquella época en España, en el año 80 sólo ETA se cobró 89 muertos dentro de las fronteras españolas. Con aquel año se inauguraba una década políticamente significativa tanto para Francia como para España, que pasarían, con tan sólo un año de diferencia -1981 y 1982, respectivamente- a estar gobernados por sendos partidos socialistas. Pero en España daba comienzo, además, la dramática realidad de los llamados "años de plomo", con una víctima de ETA cada tres días, aproximadamente.

Esta oleada de asesinatos contrasta con la cobertura que dio Le Monde al fenómeno, ya que, de las 89 víctimas citadas más arriba, el diario informó de 49 y, si hablamos en términos de atentados mortales, las páginas del vespertino sólo cubrieron 31 de los 63 reales. De esta forma, establecemos que la representación fue del $55 \%$ de las víctimas y del 49,2\% de los atentados mortales de ETA. La menor representación fue para las víctimas sin profesión específica, puesto que, de las 31 muertes que causó ETA en este colectivo, Le Monde sólo informó de ocho de esas personas. Dicho de otra forma, el vespertino dio una cobertura del 25,80\% a las víctimas mortales de ETA que no eran ni militares, ni policías, ni guardias civiles, ni políticos, ni jueces, ni abogados, ni empresarios.

A eso se añade que el género mayoritario empleado por el vespertino para informar sobre víctimas mortales del terrorismo de ETA fue el breve, con una extensión de tan sólo un párrafo para el $60 \%$ de las informaciones sobre esos asesinatos. Los breves estaban insertados en la subsección À travers Le Monde, junto a otros procedentes de cualquier país. Además, ninguna de las informaciones publicadas sobre ETA por Le Monde en 1980 contenía fotografías o elementos gráficos de apoyo ${ }^{5}$.

De ese tipo de informaciones hay una muestra significativa en el ejemplar del 24 de septiembre de 1980. Concretamente en la página 5, aparece, en la parte inferior central y entre breves de Afganistán, África Central, Irlanda del Norte, Marruecos y Vanuatu, la siguiente representación del terrorismo de ETA:

CUATRO GUARDIAS CIVILES fueron muertos el sábado 20 de septiembre cerca de Bilbao en el transcurso de un atentado terrorista. Por otra parte, el Batallón Vasco Español ha reivindicado una agresión que tuvo lugar el sábado en la ciudad vasca de Durango, que provocó cuatro heridos. Como consecuencia de estos nuevos atentados, Manuel Fraga, líder de la derecha, ha reclamado la proclamación del estado de excepción en el País Vasco.

(AFP, Reuter, UPI)

5 La parquedad fotográfica de Le Monde ha sido siempre uno de sus signos distintivos, hasta el punto de que la primera vez que el vespertino publicó una fotografía en portada fue en 2001, en referencia a los atentados del 11 de septiembre. 
Esta forma de informar sobre las víctimas es muy similar a la que se empleaba en la misma época en la Comunidad Autónoma Vasca. Así lo explica el periodista José María Calleja, que considera que durante muchos años "las víctimas han sido, por desgracia, un elemento del paisaje. Se decía: 'Han matado a un policía', pero no le ponían ni nombre ni apellidos, ni edad, ni lugar de nacimiento, ni si tenía mujer e hijos, ni si tenía aficiones (Garzón, 2006: 363)".

Para referirse a ETA, en 1980 Le Monde utilizó mayoritariamente la expresión "organización separatista”, y el término "terrorista" en tan sólo tres ocasiones, una de las cuales aparece entre comillas. Al terrorismo también se le llamó "lucha armada", lo que ya había aparecido en años anteriores y supone un calco al léxico empleado por la banda. Así es como se retrató el terrorismo de ETA en la serie de reportajes que $L e$ Monde publicó el viernes 27, el sábado 28, el domingo 29 y el lunes 30 de junio. Esta trilogía, que lleva por título "País Vasco español: el imposible apaciguamiento" tiene en el segundo de sus reportajes el de contenido más significativo. Bajo el titular "Razones de ETA” (Le Monde, 28-VI-1980: 5), el diario galo analiza a página completa - cobertura informativa del fenómeno sin precedentes en Le Monde- las "tesis de la organización separatista ETA", presentando a la banda como una organización "en la que reina la más grande democracia interna" y que no parece conocer "los problemas financieros" ya que el "impuesto revolucionario retenido 6 a los empresarios locales es de un rendimiento elevado". Además, en esta extensa segunda parte de la serie de reportajes se da voz a quienes aseguran que el País Vasco vive una situación represiva equiparable a la Francia ocupada por las tropas de Hitler durante la Segunda Guerra Mundial.

Dentro del léxico, también resulta significativo el uso de la palabra "tué" por "assassiné” para referirse a cuando alguien es asesinado por ETA. El hecho de que el verbo aparezca en participio muestra la habitual preferencia de la voz pasiva en las noticias sobre atentados mortales. Hay que recordar aquí que la manera propia de informar de Le Monde sobre este tipo de hechos es hacerlo con una primera noticia que anuncia el asesinato y una segunda en la que ETA lo "reivindica". Teniendo en cuenta esta rutina informativa, lo que ocurre con las primeras noticias sobre un atentado es que se dice quién fue asesinado -o "muerto"-pero ETA no aparece ni como sujeto paciente en esa voz pasiva. Como mucho, se hace referencia a "por unos desconocidos". Sin embargo, la organización terrorista pasa a ser la protagonista en la segunda noticia, es decir, en la que ETA "reivindica” el atentado.

El uso del término "reivindicar" también es connotativo y supone otro calco al léxico empleado por la propia ETA. Según la Real Academia Española, reivindicar significa, entre sus varias acepciones, "reclamar la

6 La terminología empleada no sólo es un calco de la de ETA, sino que hace pensar más en una institución tipo Agencia Tributaria antes que en una banda terrorista. 
autoría [de una acción]”. A su vez, reclamar quiere decir según la RAE “pedir con firmeza o exigir”, de manera que, en el caso de ETA, ésta no tenía ningún problema en que se le atribuyera el atentado; todo lo contrario, exigía -según la RAE- el reconocimiento de que habían sido ellos los asesinos. Y es así, con el propio léxico de la banda, como lo transcribe Le Monde.

En cuanto a la procedencia de las informaciones, hay que destacar la importancia que a partir de 1980 cobró el papel de las agencias de prensa para Le Monde, que desde entonces se nutre de sus teletipos y recurre a ellos para cubrir gran parte de los atentados de ETA. Como afirma Virginie Grognou, corresponsal de AFP en Madrid, la agencia era "el buzón de ETA en los años 80. El mensaje de ETA llegaba a través de la agencia. De la misma manera que ahora llegan por Gara, en los años 80 ETA concebía a AFP como una agencia más objetiva que los medios españoles, ya que es un medio internacional, y francés, y como ETA también pide la independencia de Francia, consideraba que este era el mejor medio para hacerse oír"”.

Por último, otro de los temas que se ponen de manifiesto en Le Monde durante 1980 es la extorsión a empresarios y trabajadores liberales. El vespertino recogió aquel año una noticia en la que Jaime Mayor Oreja aseguraba que ese chantaje se orquestaba en suelo francés: "Es evidente que la preparación y la planificación de estos crímenes se hacen en Francia. De la misma manera, se cometen en Francia ciertos delitos como el pago del impuesto revolucionario (exigido por ETA a los industriales vascos españoles). Es inadmisible que Francia no adopte una posición enérgica frente a este problema que reclama soluciones internacionales" (Le Monde, 17-VI-1980: 8).

Días más tarde, siguiendo en la línea de artículos en los que se da voz a las autoridades españolas, Juan José Rosón dice: “¿Qué pasaría si los separatistas corsos estuvieran en Barcelona o en la Junquera?” (Le Monde, 28-VI-1980: 7). El ministro se dirigía así a los corresponsales de la prensa extranjera en Madrid. El periódico nunca contestó ni hizo referencia alguna a esa pregunta.

\subsection{Tercera etapa. De 1981 a 1986: ETA en Le Monde durante los gobiernos socialistas en Francia y España}

El 10 de mayo de 1981, François Mitterrand venció a Valéry Giscard d'Estaing por mayoría absoluta en las elecciones presidenciales, con una participación del 85,85\%. Para el entonces director de Le Monde, Jacques Fauvet, la elección de Mitterrand suponía "la victoria de la alternancia, es decir, de la democracia" (Thibau, 1996: 397).

Entrevista de la autora con Virginie Grognou en Valencia, el 29 de marzo de 2007. 
Cuenta Sagrario Morán que durante la campaña electoral de 1981, Mitterrand lanzó la idea de crear un departamento vasco-francés, promesa nunca cumplida que habría sido una estrategia política para que muchos vasco-franceses nacionalistas apoyaran al candidato socialista, que reafirmó la posición del país vecino como tierra de asilo. Además, según Morán, Francia tenía una imagen bastante romántica de ETA como organización que se había opuesto al franquismo (Morán, 1997: 162-166). En aquel primer año de mandato, Mitterrand restauró la concesión de los permisos de residencia y de las cartas de refugiado político -ambos anulados por Giscard-para los miembros de ETA.

En octubre de 1982, en España el PSOE ganó las elecciones generales también con mayoría absoluta, por lo que se producía una similitud sin precedentes entre las políticas de ambos países vecinos. Para Felipe González impulsar las relaciones con Francia era un paso previo para conseguir una doble finalidad: la entrada de España en la CE y la ayuda para combatir a ETA. Mientras, para las autoridades francesas esto era algo secundario y las principales medidas que tomaron para luchar contra el terrorismo fueron la concesión de una amnistía en 1981, la abolición de la pena de muerte y la reiteración de su política de bienvenida de refugiados, lo que en parte provocó que los territorios galos se convirtieran en hervideros de grupos terroristas extranjeros.

Justamente ese año, Le Monde -constituyendo por tanto un reflejo preciso de la implicación política del país vecino-, tan sólo cubrió en sus páginas la cuarta parte de las víctimas mortales causadas por ETA. La cooperación francesa no se intensificó hasta 1983, con la celebración de los Seminarios Ministeriales y los consiguientes acuerdos que hicieron que los refugiados de ETA comenzaron a sentirse cada vez más inseguros en el sur de Francia. Además, se produjo un cambio de concepción por parte de Mitterrand, que se materializó en la frase "No hay refugiados que vengan de una democracia. Solamente hay criminales de derecho común” (Morán, 1997: 175-177). Por otra parte, aquel año entraron en escena los GAL, con lo que, al ser considerada ésta una de organizaciones terroristas más sanguinarias de la década de los 80 en Francia, se consiguió una mayor implicación de este país (Woodworth, 2002).

Sin embargo, un año más tarde, la representación del terrorismo de ETA en Le Monde volvió a caer hasta convertirse en la menor en toda la historia del diario, al informar de ocho muertos de los 32 que causó la banda terrorista y de cuatro atentados de los ocho mortales que efectivamente cometieron los miembros de ETA.

Si tratamos los datos de esta etapa de forma conjunta, el análisis de contenido realizado permite establecer que Le Monde sólo informó de 72 de las 202 víctimas mortales que durante esos años causó ETA, y de 56 de los 159 atentados que perpetró. Por tanto, la cobertura informativa es, en ese periodo, del 35,6\% de las víctimas y del 35,2\% de los atentados mortales. Además, el breve volvió a ser la forma predilecta de Le Monde 
para informar sobre los atentados de la banda durante este período y las víctimas con menor representación fueron los empresarios, seguidas de aquellas personas sin profesión específica.

En cuanto al léxico, entre 1981 y 1986 la fórmula más utilizada para denominar a ETA volvió a ser la expresión “organización separatista”, mientras que Le Monde sólo se refirió a ETA como "organización terrorista” en tres ocasiones.

\subsection{Cuarta etapa. De 1987 a 1997: Del primer atentado masivo (Hipercor) al asesinato de Miguel Ángel Blanco. Reacciones y primeros cambios en la forma de informar de Le Monde}

El año 1987 comenzaba con la creación de un gobierno de coalición PNV-PSOE, que coincidió en el tiempo con una nueva estrategia de ETA para obligar al gobierno a negociar tras una notable intensificación de la actividad terrorista. Ejemplo de estos nuevos atentados fueron la masacre de Hipercor en Barcelona y la de la casa cuartel en Zaragoza, ambos en junio. En el terreno informativo, llama la atención lo publicado por Le Monde a los pocos días del atentado de Hipercor:

\section{ETA asume la responsabilidad del atentado de Barcelona pero habla de "grave error"}

Que los españoles se tranquilicen: ETA militar lo hará todo para evitar la repetición del "grave error" del atentado cometido en un supermercado de Barcelona. De ahora en adelante, la organización separatista, que acepta "la responsabilidad del triste acontecimiento", velará cuidadosamente por el "carácter selectivo" de sus acciones. Presenta incluso "sus condolencias al pueblo catalán y a las familias de las víctimas". COMUNICADO DE ETA. (Le Monde, 23-VI-1987: 2)

Como puede apreciarse en este párrafo, del que ya se avisa que es una reproducción parcial de uno de los comunicados de la banda, el diario justifica a ETA y llega a pedir tranquilidad, asegurando -de forma aventurada, como pronto lo demostraría el atentado de la casa cuartel de Zaragoza-, que la organización sólo atentará a partir de entonces de forma selectiva. De nuevo, el diario da carácter de legitimidad a los asesinatos de víctimas seleccionadas; es decir, de algún guardia civil, militar o policía. Así, la noticia es "ETA sólo matará de forma selectiva" cuando debería ser: "ETA afirma que seguirá matando de forma selectiva”. Por otra parte, la idea de arrepentimiento que quiere dar Le Monde en esta noticia no se corresponde con las declaraciones que en alguna ocasión han hecho los propios miembros de ETA, quienes han asegurado sentir placer cada vez que mataban (Reinares, 2001: 82).

Mientras, en España 1987 era el año de los pactos, por un lado el Pacto de Madrid, según el cual todos los partidos -excepto HB y EA- rechazaban la violencia y, por otro, el de Ajuria Enea, en el que los firmantes reconocían en el Estatuto de Guernica "la expresión de voluntad mayoritaria de los ciudadanos vascos”. 
Al llegar 1993, el país vecino vivió un cambio de gobierno con la victoria de la coalición de centro - derecha formada por la Agrupación para la República (RPR) del alcalde de París y ex primer ministro Jacques Chirac, y por la Unión para la Democracia (UDF) del ex presidente Valéry Giscard d' Estaing. Durante este año, se agilizaron las extradiciones y unas noventa personas fueron detenidas por la policía francesa. Además, se reanudaron las expulsiones y se produjo una gran movilización de la sociedad vasca y española, sobre todo tras el secuestro de Julio Iglesias Zamora. La respuesta a todo ello fue una intensificación de los atentados contra la Ertzaintza y contra las empresas y organismos de capital francés, que sufrieron alrededor de 300 acciones terroristas (Morán, 1997: 367).

Ya en 1995, al asunto de los GAL, con datos que comenzaban a salpicar a la policía francesa, se unieron las elecciones presidenciales de mayo -en las que las autoridades centraron toda su atención- como aspectos que minimizaron la cooperación francesa para acabar con ETA. En lo policial, las actuaciones del país vecino también se redujeron mientras ETA organizaba sendos atentados contra José María Aznar y el Rey, ataques frustrados tras los cuales descendió la actividad policial francesa a la vez que se intensificaban las acciones de ETA, que acabó el año con el secuestro del empresario José María Aldaya y comenzó 1996, el mismo año en que Aznar ganó las elecciones y la derecha volvió a gobernar España, con el de José Antonio Ortega Lara, funcionario de prisiones secuestrado por ETA para conseguir la reagrupación de los presos en las cárceles del País Vasco. Cuenta Ortega Lara, que permaneció en cautiverio 532 días, que al llamar a los etarras "terroristas" éstos se sintieron ofendidos y negaron que fueran tal cosa (San Sebastián, 2003: 232).

Fue precisamente la reagrupación de presos el motivo alegado por los terroristas de ETA para secuestrar y asesinar a Miguel Ángel Blanco, víctima del atentado que en julio de 1997 conmocionó a España y a la opinión pública internacional y, como parte de ella, a la francesa, cuya prensa dio un giro, aunque este se manifestó de forma más tardía, en la cobertura del fenómeno que aquí se estudia. Como asegura Luis Veres, el asesinato de Miguel Ángel Blanco fue el "acontecimiento que hizo variar todos los puntos de vista a la hora de que el periodismo se aproximara al fenómeno terrorista” (Veres, 2006: 181).

Así, mientras en España el asesinato a sangre fría del joven concejal originó una oleada de masivas protestas que constituyeron el llamado "Espíritu de Ermua", la presión judicial y policial aumentó, con el procesamiento de la Mesa Nacional de HB y la clausura, por parte del juez Garzón, del diario Egin. En Francia también se detuvo a 50 “etarras” y, en el ámbito periodístico, Le Monde reflejó las movilizaciones en las calles con una amplitud sin precedentes. Sin embargo, la forma de llamar a los miembros de ETA seguía siendo, de forma mayoritaria y como en los años anteriores, "independentistas vascos” y "separatistas”. Ade- 
más, los corresponsales del diario hablaron del atentado contra el concejal de Ermua como "fin trágico" o "hecho dramático".

Por otra parte, las informaciones -que de forma general no habían superado el breve hasta entonces-, aumentaron considerablemente en tamaño a partir del asesinato de Miguel Ángel Blanco. Además, los periodistas comenzaron a ofrecer antecedentes en sus informaciones. Sin embargo, y aunque la cobertura aumentó con respecto a la etapa anterior, esta todavía fue del 58,8\% de las víctimas -con informaciones de 146 sobre las 248 reales-y del 45,8\% de los atentados mortales -con informaciones de 72 de los 157 reales-. Y, además, en ocasiones esa baja representación se aderezaba con piezas tituladas de forma connotativa, como es el caso de la cronología: “Treinta y ocho años de lucha contra el gobierno español”.

Con todo, y aunque los cambios en la forma de informar comenzarían a percibirse de forma más visible en 1998, puede decirse que el vespertino dio un salto cualitativo, ya que concedió una entrevista de gran contenido a Jaime Mayor Oreja y uno de los artículos de opinión más extensos, titulado "ETA deslegitimada” (Le Monde, 15-VII-1997: 10), que dio lugar a que la corresponsal, Marie-Claude Descamps, se preguntara si la banda, a la que seguía llamando "organización separatista ETA", acababa de "suicidarse" disparando las dos balas que ponían fin a la vida de Miguel Ángel Blanco. También hay que señalar en esta etapa un leve aumento en la cobertura de víctimas sin profesión específica, debida, en gran parte, a la masacre de Hipercor.

\subsection{Quinta etapa. De 1998 hasta la actualidad: Le Monde cambia notablemente su forma de informar sobre ETA en lo cuantitativo pero mantiene el léxico}

El año 1998 fue el año de Estella- Lizarra, pacto que supuso la ruptura con una larga etapa de colaboración entre el PSOE y el nacionalismo democrático (1987- 1998). Aquel año el PNV se decidió a dialogar con ETA, en unos contactos que comenzaron en enero y prosiguieron durante todo el verano, dándose la coyuntura de que el PSOE acababa de abandonar el gobierno vasco y que la banda terrorista había puesto como condición para el cese de la violencia la ruptura de PNV y EA con PSOE, PP e IU, partidos considerados "españolistas".

En octubre se celebraron elecciones autonómicas y, tras estas, que no tuvieron resultados relevantes más allá de la bipolarización que beneficiaba a HB y PP, se produjo un alto el fuego. Durante este período, 200 etarras fueron excarcelados y unos 135 reagrupados. Además, 60 de los 150 emigrados a Francia volvieron al País Vasco (Morán, 1997: 426). Pero los miembros de ETA querían más, por lo que se movilizaron a favor de los presos y, finalmente, rompieron el alto el fuego, tras 14 meses y 16 días, el 28 de noviembre de 1999. 
El retorno a los atentados mortales se hizo efectivo en enero de 2000, mes en que la banda asesinó, entre otros, a José Luis Rodríguez de Lacalle, periodista y fundador del foro de Ermua. Era la segunda vez que ETA atentaba mortalmente contra un profesional de los medios de comunicación -la primera fue contra José María Portell, en 1978- y aquel año también lo intentó contra Aurora Intxausti, de El País, Juan Francisco Palomo, de Antena 3, contra Carlos Herrera, de RNE y contra las instalaciones de El Correo Español y El Diario Vasco.

Un año más tarde, el panorama internacional estuvo marcado por la masacre terrorista más sangrienta de la historia: los atentados contra las Torres Gemelas del 11 de septiembre. Esta gran matanza, paradigma del terrorismo indiscriminado y llevada a cabo en Nueva York por miembros suicidas de Al Qaeda ${ }^{8}$, cambió la concepción que muchos medios de comunicación internacionales tenían de ETA. Como señala Luis Veres, a partir de esa fecha la agencia de noticias estadounidense Associated Press (AP) dejó de hablar de esta banda terrorista como de una simple guerrilla vasca (Veres y Catalán, 2004). Sin embargo, este cambio de concepción, o al menos de denominación de ETA, no se dio en Le Monde. El vespertino, si bien empleó aquel año el término "terrorismo" para referirse a las acciones de ETA en cinco ocasiones, denominó "organización separatista” a la banda en las siete ocasiones en que ésta fue calificada de alguna manera.

No fue hasta 2002, mientras en España el juez Garzón iniciaba los trámites para ilegalizar Batasuna, cuando se produjeron cambios notables en la manera de informar sobre las acciones terroristas de ETA. Aquel año, a pesar de que Le Monde tampoco calificó como "terrorista" a la banda vasca, el diario empleó tres veces la palabra "terrorista" para referirse a sus miembros. Además, todos los atentados mortales de ETA fueron representados por el diario con seguimiento informativo y la pieza mayoritaria a la hora de informar fue la noticia a cuatro columnas, algo que constituyó una cobertura informativa sin precedentes ${ }^{9}$.

Dos años más tarde, mientras se descubría que Josep-Lluis Carod Rovira (ERC), socio del PSC en el gobierno catalán, había negociado con ETA un alto el fuego sólo para Cataluña, la presión policial sin precedentes tanto en España como en Francia debilitaba cada vez más a ETA. Era 2004, el año en que Madrid sufrió el peor atentado de la historia española, cometido por el terrorismo islamista.

$\mathrm{Al}$ año siguiente, cuando el Gobierno esperaba que ETA dejara por fin las armas, la banda hizo estallar un coche bomba Getxo, atentado en el que resultó herido un ertzaina. No obstante, las esperanzas de las au-

8 La principal diferencia de Al Qaeda con ETA es que la banda vasca practica, como el IRA, el terrorismo regional. Su ámbito de operaciones se circunscribe a España y no atenta en Francia, país que históricamente ha sido su refugio y donde considera suyas tres provincias, las de "Euskadi Norte" o País Vasco Francés.

9 La disposición mayoritaria de las informaciones sobre atentados mortales de ETA en Le Monde es el breve o noticia de un párrafo.

doxa.comunicación | nº 9 
toridades y de la sociedad española aumentaron hasta un nivel sin precedentes cuando ETA anunció, el 21 de marzo de 2006 -comenzaría a hacerse efectivo el viernes, día 24- un alto el fuego "permanente", tal y como lo denominó la propia banda. Los meses pasaban mientras el presidente, José Luis Rodríguez Zapatero, llevaba a cabo el llamado "Proceso de paz" para encontrar "una salida dialogada de la violencia", tal como explicó el propio ejecutivo socialista. En ese proceso, entendido por el PP como una negociación con concesiones para los terroristas, Rodríguez Zapatero nunca contó con el apoyo de esta parte de la oposición.

Así, en un ambiente político en el que primaba la bronca sobre el consenso de las diversas formaciones, concretamente seis meses y cuatro días después de que ETA lanzara el comunicado de "alto el fuego permanente", la banda colocó una furgoneta bomba en el aparcamiento subterráneo de la nueva Terminal T4 de Barajas. El resultado de este atentado, el primero de resultado mortal después de más de tres años, fue el fallecimiento de Diego Armando Estacio y Carlos Alonso Palate, dos ciudadanos ecuatorianos que descansaban en el interior de su vehículo.

A ellos la corresponsal de Le Monde, Cécile Chambraud, se refirió simplemente como a "dos ecuatorianos" (Le Monde, 2-I-2007: 6). La periodista, que recuerda cómo los hechos le sorprendieron de camino al mismo aeropuerto $^{10}$, escribió un total de tres piezas informativas sobre el atentado, acompañando la más amplia -a cinco columnas y con el apoyo de una cronología- de una fotografía en la que se ve a policías y bomberos en el lugar de la explosión. Se trata de la fotografía más grande dedicada a un atentado de ETA, con un ancho equivalente a tres columnas de texto.

Además, Le Monde publicó el segundo editorial que el diario ha escrito sobre la banda en toda su historia. En él, ETA es retratada como una "organización separatista armada vasca”, expresión que, junto a la de "organización clandestina”, apuntada por la corresponsal en la noticia más amplia, constituyen las únicas dos ocasiones en que la banda es descrita de alguna manera en las páginas del diario.

De forma general, desde el atentado contra Miguel Ángel Blanco hasta la actualidad, la cobertura que Le Monde ha hecho del terrorismo de ETA ha sido del $94 \%$ de las víctimas y del $93 \%$ de los atentados mortales de la banda. Como puede verse, en lo cuantitativo esa representación ha aumentado visiblemente, aspecto que contrasta con el carácter estático de la denominación y representación de ETA a través del léxico. En concreto, desde el atentado contra el concejal de Ermua hasta el de Barajas, ETA fue representada en 48 ocasiones como "organización separatista" frente a una sola como "organización terrorista" y los etarras fueron denominados mayoritariamente "independentistas”. Así, aunque Cécile Chambraud asegura que

10 Entrevista de la autora con Cécile Chambraud en Madrid, el 30 de junio de 2007. 
ella considera y se refiere a ETA y a sus miembros con el calificativo "terroristas·, esta palabra no aparece en ninguna de las noticias redactadas por esta corresponsal. La única referencia al término a partir de entonces la encontramos en la página web del diario, concretamente, en la noticia de la detención de Txeroki en territorio galo.

Durante 2007 y 2008, ETA ha cometido seis atentados mortales con un total de siete víctimas. En la cobertura informativa que de esta realidad hace Le Monde, sorprenden titulares en tono justificador del tipo "ETA responde con un triple atentado a la prohibición de sus escaparates políticos” (Le Monde, 23-IX-2008: 8). Sorprende también que la forma en que se describe a la banda siga siendo "organización separatista vasca". Y sorprende sobre todo en una época en la que se da una "excelente cooperación entre las policías francesa y española en la lucha contra ETA”, como ha declarado recientemente la ministra del Interior gala, Michèle Alliot-Marie (Agencia EFE, 9-XII-2008).

Además, un año después de que sendos presidentes de Francia y España cerraran en la XX Cumbre Hispano-francesa un acuerdo "decisivo" para prevenir atentados y perseguir a los etarras en ambos países, Le Monde explica, bajo el titular "Los nacionalistas vascos bajo la presión de Madrid”, que el gobierno español y la justicia "se esfuerzan por impedir al movimiento nacionalista radical presentar listas a las elecciones de marzo”. De forma simultánea, el diario ha publicado en su página web un listado con los partidos nacionalistas vascos, en el que incluye a ETA como una formación política más ${ }^{11}$.

\section{Conclusiones}

La primera conclusión a la que conduce la investigación realizada es la escasa representación que Le Monde concede al terrorismo de ETA. De forma global, y teniendo en cuenta desde el primer atentado hasta el último, esta cobertura es del 55,9\% de las víctimas y del 41,02 de los atentados mortales perpetrados por la banda. Es por este motivo que el volumen de las informaciones extraídas sólo alcanza las 654, aun cuando el trabajo de campo -como se señalaba en las primeras líneas- está compuesto por aproximadamente 5.000.

11 http://www.lemonde.fr/web/recherche_breve/1,13-0,37-1069028,0.html. 
Gráficos I y II: Número real de víctimas y de atentados mortales y número de víctimas y atentados sobre los que informa Le Monde
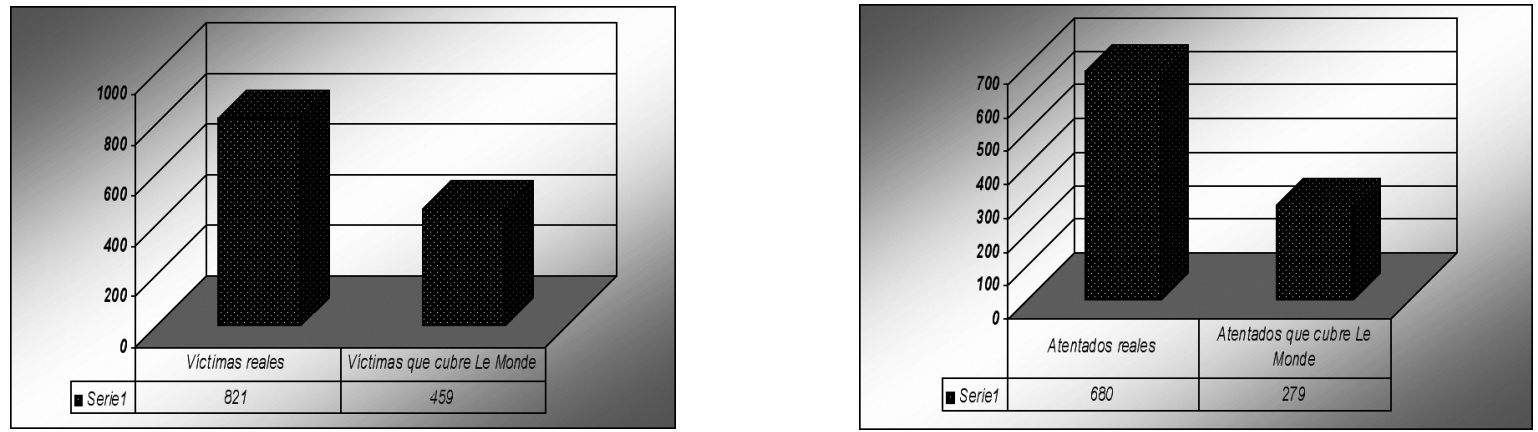

Del total de las víctimas, aquéllas a las que el vespertino da la menor representación son, de forma global, aquellas que no pertenecen a ningún colectivo profesional específico. En este caso, el diario recoge informaciones sobre 96 de las 274 víctimas totales, con lo que la cobertura desciende en este caso hasta el $41 \%$, haciendo de las personas sin cargo concreto el sector de víctimas menos representado en Le Monde. Aquí hay que apuntar, además, que, a excepción de los atentados masivos, como el de Hipercor, las víctimas sin profesión conocida de las que informa el vespertino son aquéllas que pierden la vida en los atentados contra políticos, militares o alguna personalidad que sí tenía un cargo específico. El resto de víctimas mortales, como por ejemplo los empleados de comercios cercanos al lugar de la explosión de una bomba de ETA, tienen una representación nula en Le Monde.

De este modo, al otorgar mayor visibilidad a los miembros del Ejército, la Policía o la Guardia civil que a personas sin profesión determinada -y dado que del resto de profesiones mencionadas ETA no comenzará a matar de forma continuada hasta los años 80-, en los primeros años de atentados de la banda el diario ofrece una visión errónea de la realidad, dando la impresión de que ETA sólo atenta contra militares, guardias civiles y policías. Esto ayuda a la creación de un imaginario de guerra justa contra la opresión, proporcionando una visión maniquea en la que los etarras luchan por la libertad de su pueblo y que tiene como consecuencia final la legitimación de los atentados mortales de la banda.

Otra de las conclusiones es la invisibilidad de estas víctimas sin profesión específica. Así, cuando estas personas mueren en atentados contra un personaje conocido, en el 97\% de esos casos las informaciones anuncian el nombre de la víctima con cargo específico y el nombre de las personas que simplemente pa- 
saban o se encontraban en el lugar o bien no aparece o bien aparece escrito incorrectamente. Esa imprecisión, que podría ser la propia de atentados masivos por la falta de espacio para nombrar a todas las personas muertas -en estos casos Le Monde nunca enumera a las víctimas mortales-, se mantendrá hasta el de de Barajas, el último analizado, en el que perdieron la vida dos hombres, Diego Armando Estacio y Carlos Alonso Palate, y a los que el vespertino se refiere simplemente como a "dos ecuatorianos".

\section{Gráfico III. Víctimas sin profesión específica}

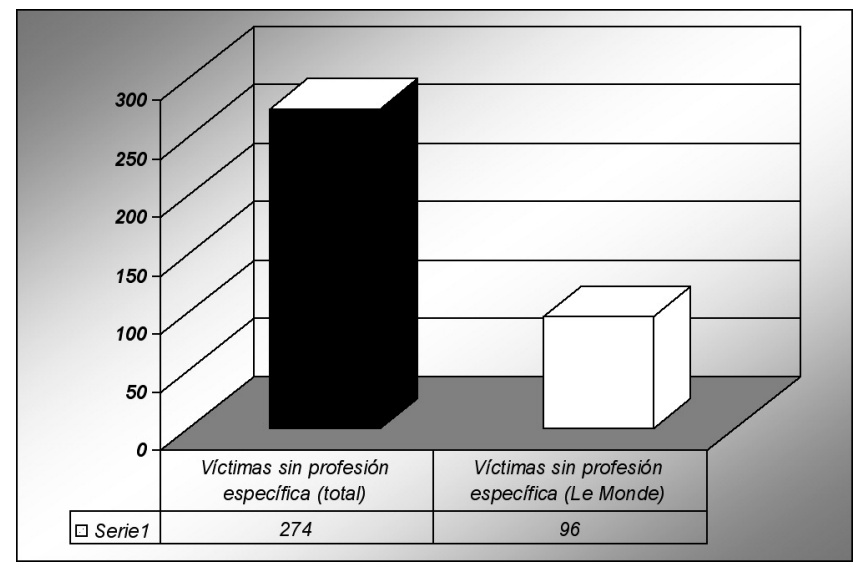

También rotunda la conclusión del análisis referido al léxico empleado por el vespertino para referirse a la banda terrorista. Si en las páginas del diario se califica de alguna manera a ETA en 230 ocasiones, de ellas 163 coinciden en el término "separatista”, 31 “independentista” y cinco “terrorista”. En las 36 ocasiones restantes, el vespertino emplea otras expresiones, tales como "organización revolucionaria" u "organización clandestina”, empleadas en menos de cinco ocasiones cada una. Este tratamiento atenuado de la banda no ha experimentado cambios significativos en toda su historia, ni tras el atentado de Miguel Ángel Blanco ni a raíz de los del 11 de septiembre en Nueva York o los del 11 de marzo en Madrid. 


\section{Gráfico IV. Cómo Le Monde se refiere a ETA}

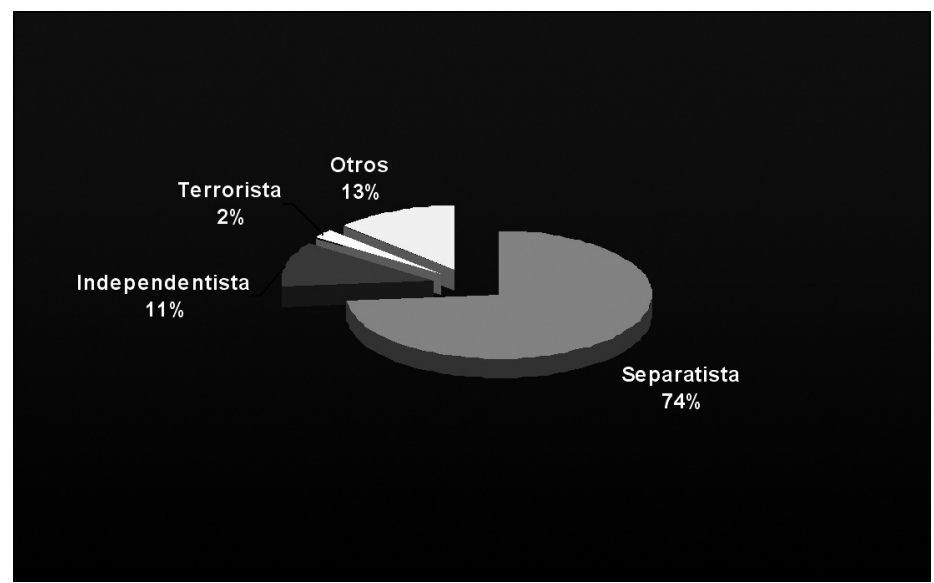

"Separatistas" vuelve a ser el adjetivo con el que Le Monde se refiere también de forma mayoritaria a los miembros de ETA, en este caso en 31 ocasiones frente a las 20 en las que el diario emplea "independentistas"; 13 "terroristas" y cinco "activistas". Puesto que los miembros de ETA son retratados de alguna forma en un total de 104 ocasiones, las 40 restantes son otras formas, como "partisanos" o "guerrilleros", empleadas en menos de cinco ocasiones cada una.

Gráfico V. Cómo Le Monde se refiere a los miembros de ETA

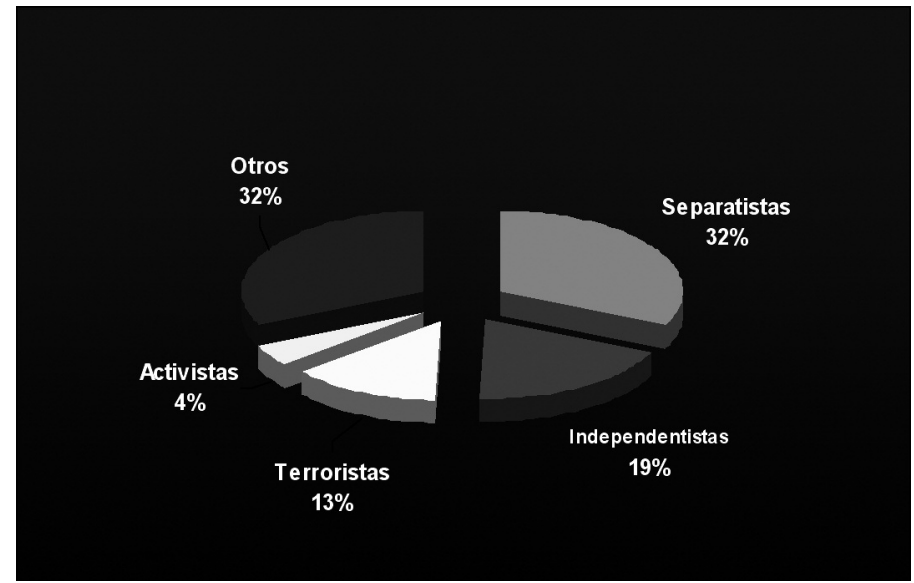


A la escasa aparición del término "terrorista”, en un total de 18 ocasiones, contribuye el rechazo expreso de este término por parte de la principal agencia de prensa de la que se nutre Le Monde a la hora de informar sobre la banda. Así, la corresponsal de AFP reconoció a la autora la prohibición del empleo -aunque sí está permitido su uso interno en la redacción de la agencia- del término "terrorista" a la hora de redactar noticias sobre ETA para su difusión. El porqué de esa prohibición, que constituye a la vez la única norma con la que cuenta AFP para informar del fenómeno, no pudo ser explicado por la corresponsal, Virginie Grognou, que reconoció no saberlo. Por su parte, el director de la agencia, con el que se ha intentado una comunicación en repetidas ocasiones, la ha declinado en todo momento.

En cuanto a las pautas empleadas Le Monde, el diario no cuenta con normas definidas con las que informar sobre ETA (Thibau, 1996). Esa falta de reglamentación es atribuida a "la libertad con la que cada periodista puede informar en Le Monde”, tal como se justificó la corresponsal del diario al ser preguntada sobre el asunto.

Esa caracterización de ETA como grupo u organización "separatista" no se da en Le Monde a la hora de retratar a otros grupos terroristas de los que informa el diario. Así, cuando se trata de representar a grupos franceses, como el FNLC, éstos sí son considerados terroristas, resaltando los peligros que pueden tener para Francia, que a ojos de Le Monde es "una sociedad que se ha degradado bajo los efectos de concesiones permanentes a la familia nacionalista”, tal como el diario publica en 1990.

En referencia a otros fenómenos terroristas europeos, como el IRA, este tiene mayor presencia en Le Monde que ETA y sus atentados resultan más visibles al lector por la mayor presencia del nombre del grupo en los titulares, así como por la construcción y redacción de éstos en voz activa, en la que el IRA siempre es sujeto agente del hecho sobre el que se informa. En cuanto a los grupos terroristas que operan en todo el ámbito internacional, como Al Qaeda, según los corresponsales entrevistados, estos son los que más interesan al lector francés, que ven más posible un ataque del terrorismo islamista que el de ETA.

En cuanto a la actitud del lector francés hacia el terrorismo de ETA, la corresponsal Virginie Grognou apela a la escasa empatía de este con el problema de ETA por no entender "cómo en un país con 17 gobiernos autonómicos alguien puede matar por conseguir aún mayor independencia"12. Sin embargo, las corresponsales entrevistadas coinciden en que esa duda no motiva a los lectores y, "simplemente, no les interesa el problema porque lo consideran algo ajeno".

12 Entrevista de la autora con Virginie Grognou en Valencia, el 29 de marzo de 2007. 
Pues bien, al desinterés que siente el lector francés por el fenómeno terrorista de ETA, del que las periodistas entrevistadas desconocen el porqué, tal vez esta investigación proporcione algunas claves. Así, la mitigación de los actos terroristas mediante una cobertura sesgada en número de atentados y víctimas hasta 1998 puede haber contribuido a una consideración de ETA como un grupo menos violento de lo que ha sido en realidad. Los entrevistados atribuyen esa falta de información a que los atentados muy continuados, por repetitivos, contribuyen también a la pérdida de interés para el lector francés. Es por eso que tanto las agencias como Le Monde optan por cubrir sólo los atentados con más víctimas, como demuestran también las cifras.

Por otra parte, como hasta esa fecha el espacio que de forma general se ha otorgado a las noticias sobre atentados de la banda es el breve (véase el gráfico IV), situado en una parte poco visible de la página, estos pasan muchas veces desapercibidos a los ojos de un lector convencional. Al llegar a este punto, en necesario remarcar la dificultad que se da en muchos casos para encontrar esas piezas informativas, incluso para alguien que investiga al respecto. Por ello, no es de extrañar que un lector diario que sólo hace uso del periódico para informarse de forma general no repare en las informaciones que Le Monde publica sobre ETA.

Gráfico IV. Disposición mayoritaria de las informaciones

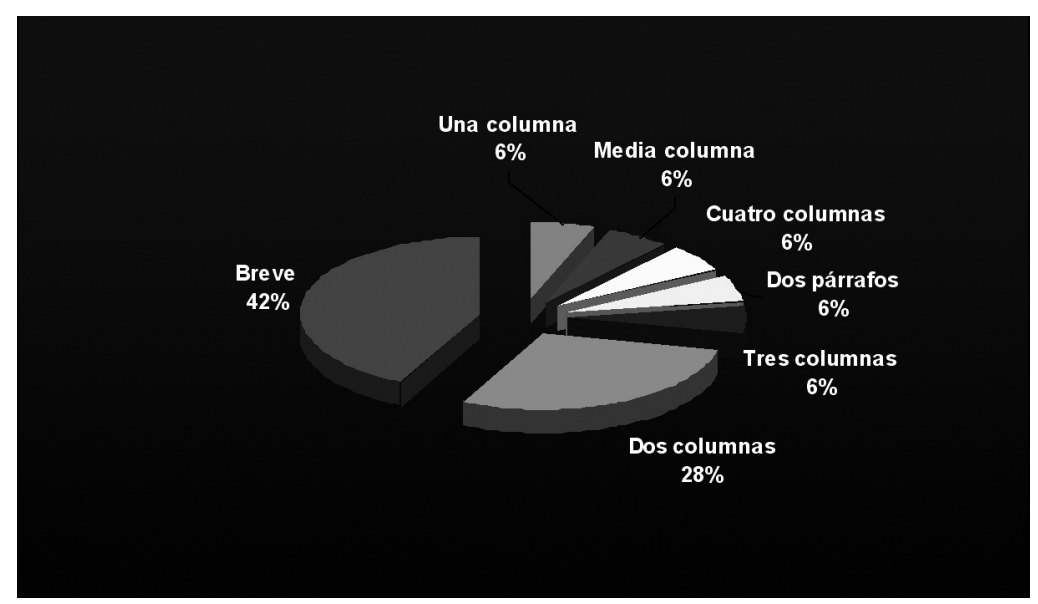

Cuando esas informaciones sí son visibles, en ellas el tratamiento dado a ETA y a sus miembros es, de forma mayoritaria y como se ha visto, a través de la expresión "organización separatista”, lo que exime a la banda del componente criminal que, por definición, tiene un grupo terrorista. Al contrario de lo ocurrido con los aspectos cuantitativos, que en 1998 experimentan un cambio significativo y constante hasta la actualidad, 
la consideración positiva de ETA mediante el léxico empleado para caracterizar a la banda nunca se eliminará y, por el contrario, se verá reforzada en las múltiples informaciones en las que la banda es comparada con otros grupos terroristas franceses, europeos o internacionales. Esa forma de denominar a ETA tiene carácter estático y permanente, ya que no sólo es algo implícito, como ocurre con el hecho de informar preferentemente de atentados masivos, sino que constituye la única norma con la que cuentan los periodistas franceses a la hora de informar sobre el terrorismo etarra, y que es la de no llamar "terrorista" a ETA.

En definitiva, a la minimización de las informaciones se une la mitigación del componente terrorista de ETA y estos, sumados a las comparaciones favorables con otros grupos terroristas y la falta de reglamentación de Le Monde y las agencias de prensa, configuran un discurso incompleto, parcial y en ocasiones erróneo que, trasladado a los lectores, genera, como los propios corresponsales reconocen, incomprensión en la opinión pública francesa.

Es necesario apelar en este punto a la responsabilidad de los informadores, cuya misión es promover el interés del lector, a quien de forma fundamental se deben con su labor informativa. En este sentido, en lugar de informar sólo de ciertos atentados o aspectos del terrorismo de ETA porque el fenómeno "no interesa", cabría aquí apelar a la reflexión y preguntarse si ha sido la forma de informar mantenida durante décadas la que ha producido esa mezcla de desinterés e incomprensión en el receptor del mensaje. Si la respuesta es afirmativa, es entonces cuando deberían ponerse en marcha los mecanismos para corregir errores y deficiencias en esos modos informativos. Así, de la misma manera que Le Monde da un salto en lo cuantitativo en 1998, convendría que tanto el propio medio como aquellos a los que adquiere parte de las informaciones hicieran una revisión, preguntándose también por qué se emplea un léxico no ajustado a la realidad de una banda que ha causado más de 827 víctimas mortales y que ha organizado muchos de los atentados en suelo francés.

Es por tanto una misión de los corresponsales subsanar esos fallos e intentar reconducir la atención de los lectores, aportando para ello antecedentes y las claves para entender la situación política y social de España y del País Vasco, ese territorio que une geográficamente a ambos países. En el fondo, sería ésta una labor muy grata, ya que serviría como impulso para acercar la opinión pública francesa al problema de ETA y, a la vez, constituiría el justo tributo a las víctimas, silenciadas la mitad de ellas por el primer diario del país vecino. 


\section{Referencias bibliográficas}

AAVV. (2003): Terrorismo, víctimas y medios de comunicación, Madrid: Fundación Víctimas del Terrorismo- Federación de Asociaciones de Prensa de España.

Antolín, Matías (2003): El olor del miedo, Madrid: Temas de hoy.

Calleja, José María (2002): ;Arriba Euskadi! La vida diaria en el País Vasco, Madrid: Espasa Calpe.

Diezhandino Nieto, Ma Pilar (2007): Periodismo y poder. Políticos, periodistas y ciudadanos voluntariamente desinformados, Madrid: Pearson educación.

Domínguez, Florencio (2003): Dentro de ETA. Madrid: Punto de lectura.

- (1999): “Los medios ante el terrorismo de ETA”, en Periodistas ante conflictos. El papel de los medios de comunicación en situaciones de crisis, Navarra: Eunsa.

Garzón, Baltasar (director) (2006): La lucha contra el terrorismo y sus límites. Madrid: Adhara.

Morán Blanco, Sagrario (1997): ETA entre España y Francia, Madrid: Editorial Complutense.

- (2004): Pnv-Eta: La Historia De Una Relación Imposible. Madrid: Tecnos.

Muñoz-Alonso, Alejandro (1982): El terrorismo en España. El terror frente a la convivencia pluralista en libertad, Barcelona: Planeta.

Núñez Ladevéze, Luis (1979): El lenguaje de los “media”: Introducción a una teoría de la actividad periodística, Madrid: Pirámide.

- (1995): Introducción al periodismo escrito, Madrid: Ariel.

- (2004): Mensajes periodísticos y sociedad del conocimiento, Madrid: Fragua.

Pizarroso Quintero, Alejandro (1990): Historia de la propaganda. Madrid: Eudema Universidad.

- (1994): Historia de la prensa, Madrid: Editorial Centro de Estudios Ramón Areces.

Portell, José Ma (1977): Euskadi:Amnistía arrancada, Barcelona: Dopesa.

Pulgar Gutiérrez, Belén (2004): Víctimas del terrorismo 1968-2004. Madrid: Dykinson.

Reinares, Fernando (2001): Patriotas de la muerte, Madrid: Taurus.

- (2003): Terrorismo global, Madrid: Taurus.

Rivas Troitiño, José Manuel (1992): Desinformación y terrorismo: análisis de las conversaciones entre el Gobierno y ETA en Argel (enero-abril 1989) en tres diarios de Madrid, Madrid: Editorial de la Universidad Complutense. 
San Sebastián, Isabel (2003): Los años de plomo. Memoria en carne viva de las víctimas, Madrid: Temas de hoy.

Schaffert, Richard W (1992): Media Coverage and Political Terrorists. A quantitive analysis, Nueva York: Praeger.

Setién Martínez, Francisco José (1993): Terrorismo y prensa en la transición política española: 1976-1986 (Tesis Doctoral), Madrid: Facultad de Ciencias de la Información, Universidad Complutense de Madrid.

Soria, Carlos (coord.) et al. (1987). Prensa, paz, violencia y terrorismo. La crisis de credibilidad de los informadores, Pamplona: EUNSA.

Thibau, Jacques (1996). Le Monde 1944-1996. Histoire d'un journal, un journal dans l'histoire, París: Plon.

Tuman, Joseph S (2003). Communicating Terror. The rhetorical dimensions of terrorism, California: Sage publications.

Tusell, Javier (coord.) et al (1995), Historia de la transición y consolidación democrática en España (1976-1986). Congreso Internacional. Volumen II, Madrid: Editorial de la UNED.

- (2005): Dictadura franquista y democracia, 1939- 2004. Historia de España, XIV, Barcelona: Crítica.

Uriarte, Eduardo (1998). “La manipulación de ETA por la prensa del movimiento”. Zer. Revista de Estudios de Comunicación.

Van Dijk, Teun A.(1987), Critical news analyisis (facsímil introductorio para el Instituto de Semiótica y Comunicación), Granada.

Veres Cortés, Luis (2006): La retórica del terror. Sobre lenguaje, terrorismo y medios de comunicación. Madrid: Ediciones de la Torre.

Veres Cortés, Luis y CATALÁN, Miguel (2004). Estrategias de la desinformación, Valencia: Editorial de la Generalitat Valenciana.

Woodworth, Paddy (2002): Guerra sucia, manos limpias. ETA, el GAL y la democracia española, Barcelona: Crítica.

\section{Otras referencias}

654 piezas informativas de cualquier sección de Le Monde.

Dos editoriales de Le Monde.

Entrevista a Virginie Grognou, corresponsal de l'Agence France Presse, en Valencia, el 29 de marzo de 2007.

Entrevista a Cécile Chambraud, corresponsal de Le Monde, en Madrid, el 30 de junio de 2007. 